\title{
Design recommendations for the development of a Digital Storytelling mobile application
}

\author{
Elisa Rubegni \\ University of Lugano - USI \\ Via Buffi 13, 6900 \\ Lugano, Switzerland \\ elisa.rubegni@usi.ch
}

\author{
Luca Colombo \\ University of Lugano - USI \\ Via Buffi 13, 6900 \\ Lugano, Switzerland \\ luca.colombo@usi.ch
}

\author{
Monica Landoni \\ University of Lugano - USI \\ Via Buffi 13, 6900 \\ Lugano, Switzerland \\ monica.Iandoni@usi.ch
}

\begin{abstract}
This paper focuses on the educational benefits of Digital Storytelling (DST) in the context of a primary school and on the importance of a DST application that supports teaching strategies and pedagogical objectives (as defined by the school curriculum). The work presented here is part of a 4-year longitudinal study aimed at understanding how to design an application that supports collaborative DST as educational practice in schools with children aged 6 to 11. In this paper, we describe how a typical case study has been conducted and how we used the Narrative Activity Model (NAM) as a framework to guide the activity analysis and to organize our findings. The result is a set of users' needs and guidelines for the development of an innovative DST application to be used in a formal learning context.
\end{abstract}

Mobile learning. Children-Computer Interaction. Digital Storytelling.

\section{INTRODUCTION}

The last decade has seen a growth in the use of mobile technology (laptops, tablets and smartphones) in education. This phenomenon, also known as mobile learning, is defined by O'Malley et al. [8] as "any sort of learning that happens when the learner is not at a fixed, predetermined location, or learning that happens when the learner takes advantage of learning opportunities offered by mobile technologies." For some researchers this definition is quite techno-centric and does not focus on the whole learning experience which includes portability, privacy, spontaneity, situatedness and informality [5]. In our opinion, the definition of mobile learning experience should go beyond the simple use of mobile devices to support the learning process, and include the interaction between teachers, learners and educational processes. The use of mobile devices should focus on the overall learning experience by including all its players, processes, inputs and outcomes.

Mobile learning [6] is a relatively recent field of study and many issues still need to be explored. For instance questions like what is the best way to introduce technology in schools? what are the most effective pedagogical approaches? and what are the most successful teaching practices? are yet to be answered. Mobile technology changes the nature of learning and teaching by substantially modifying the way pupils and teachers access and manipulate information. Indeed, teachers are important stakeholders in supporting the introduction, development, and adaptation of innovative solutions for education.

The interest that researchers and educators increasingly manifest towards the introduction of Digital Storytelling (DST) in education is motivated by the educational benefits digital technology could foster in such contexts. DST encompasses the range of activities that blend story telling and narrative creation with digital technologies. Furthermore, DST complements the role traditionally held by storytelling as a teaching/learning tool. DST encompasses the range of activities that blend story telling and narrative creation with digital technologies. In child development, storytelling and the creation of narrative have the purpose of shaping, giving structure and significance to the world around them and their individual experiences.

In addition, storytelling facilitates pedagogical and psychological development such as children's use of language and other forms of creative selfexpression (i.e. drawing, acting, etc.) as well as their social skills. The development of a positive collaborative and social behaviour is one of the most important pedagogical objectives in a primary school curriculum. Indeed, building on a constructivist perspective [9], group interaction and sharing in a creative activity can make the learning 
process particularly effective. According to Nicolopoulou [7], when creative activities are carried out in groups, they imply negotiation with the other members of the team, and therefore are a way of training social skills. Moreover, according to $[15,1]$, in order to introduce technology and innovations in the learning process it is relevant to consider teaching strategies and pedagogical objectives defined by the school curriculum.

Our study aims at understanding how to design an application that supports digital storytelling as educational practice in schools. This research pays particular attention to group-based story creation in a context of formal learning, and the educational benefits it can foster. We have been conducting a case study to explore the potential of DST in an elementary school, and to elicit requirements for the design of a mobile application. The research went on for four years, we worked in an elementary school in [12] and we involved three teachers and their students $(\sim 80)$. Using a longitudinal approach we established a long-term partnership with pupils and teachers which allowed us to investigate the learning context in depth and to define appropriate user requirements for the DST application. During these years, we have been running many activities. In this paper, we present just one part of the fieldwork carried out in the school in order to provide an exemplification of the type of activity we have done with the user group. However, the results reported here are outcomes of the entire longitudinal study. Findings are organized as users' needs and guidelines for the development of the DST application for schools. In the following pages, we present the relevant literature, an example of the activities carried out at school and the collection of guidelines we elaborated.

\section{RELATED WORK}

Previous research shows that mobile technology may be effective in creating digital stories in formal learning environments, both inside the classroom as well as during a field trip [e.g.15]. Teachers typically take pupils to art/science museums or to natural attractions/parks in order to promote more direct access and a hands-on approach to concepts and theories discussed in class. Many studies have already explored the use of mobile technology to aid learning/teaching activities, inside and outside the classroom. For instance, Halloran et al. [4] explore the use of digital technology in supporting literacy skills by mixing analogue and digital technologies for gathering media/content outside the classroom for story creation. Regarding DST in an educational context, an interesting attempt to introduce digital technology at school is POGO Story World [13]. POGO is a physical environment made of tangible objects that produce media content that children can use to compose their stories. More recently, the CASTOR (Context Aware STORytelling) project [10] focused on the development of a mobile-based authoring system that allows children to collect and modify material on a single device, in this case a tablet. Many mobile applications for DST can be found on the market but in most cases they are more entertainment-oriented rather than educationoriented. Applications such as StoryKit, Story Dice, YouFable allow children to produce stories but do not have any explicit educational intent nor are they connected to existing school curricula. This is where our DST application aims to differentiate.

\subsection{Research questions}

Most of the existing studies on DST are of a purely experiential nature, focusing on a limited number of activities captured in a short time span. In contrast we decided to use a longitudinal approach to better understand the school practices as well as the educational context over a longer period of time. Thanks to this choice we had the opportunity to observe school activities within all five grades of an elementary school and to work with three teachers. Through our study we aim at eliciting the requirements for an application that effectively supports the achievement of educational goals as defined by the school curriculum.

In our research, we tried to address two main questions:

- How could we support group narrative creation through the use of mobile digital technology in a formal learning context?

- What are the main features of a mobile application to support the development of literacy skills (as defined by the school curriculum) in a primary school?

The following section gives an overview of the study setting and the methods used to gather and analyze data.

\section{STUDY SETTING}

Our study addressed educational practices related to the creation of stories with children in the elementary school age-range (more precisely from $3^{\text {rd }}$ to $5^{\text {th }}$ grade, i.e. children aged 8 to 11 ). According to the Leonardo Da Vinci school's curriculum [12], children this age need to develop various linguistic competences (phonology, spelling, morph syntax, and lexicon) and to learn how to write various types of narrative (fairy tale, fable, tale, myth and legend). Other important achievements are the development of social attitudes, the improvement of self-esteem and the development of self-evaluation skills. To accomplish this teachers often ask children to work 
in groups in order to stimulate them to interact with their peers [12]. Teachers see narrative writing as an opportunity for improving both literacy and social skills. Children have to invent a story (e.g. fable) and often teachers have them work in groups. The writing laboratory is an activity during which children create stories, and it is held two hours a week. We participated in several of these sessions and we studied the activities involved in the creation of stories through repeated observations. During these sessions, we used the same protocol as well as the same set of techniques illustrated below. We analyzed the activities of both children and teachers during the writing laboratory. In order to assess the breakdown and breakthrough of the activity, we observed the class throughout all the phases of story creation; exploration, inspiration, production and sharing. We interviewed - using contextual inquiry [11] - teachers before and after the activity, and we conducted focus groups with pupils at the end of each study session. In contextual inquiry, teachers answered our questions and showed us the material used by the instructors (e.g. the books used for teaching) and produced by the children (the stories).

We interviewed teachers both before and after the study. Before the study we investigated:

- children's skills and attitudes, and their ability to use technology;

- how technology is used at school;

- the educational objectives and expectations of the storytelling activity.

- While after the study we focused on:

- children's activity alone and in groups;

- the learning process;

- quality of the outcomes.

We observed the activity during the writing laboratory in order to gain insights about:

- breakthrough and breakdown of using digital and analogue artefacts for content production (pen and paper in the explorative study, tablet and desktop computer at a later stage);

- children's individual and group activities;

- interaction among children and teachers.

During focus groups we mainly aimed at assessing children's self-perception about:

- $\quad$ specific learning achievements;

- interaction with their peers and the teacher;

- positive and negative aspects of the storycreation experience.
The data gathered were analyzed and, from this we elicited a set of user needs to design our application. The corpus of data was quite rich and heterogeneous, e.g. researcher notes from observation, transcription from interviews and postits from focus groups. The analysis of each type of data was done separately using specific techniques. For instance, the interview transcriptions were analyzed with open coding that allowed us to identify the most relevant activity instances. The triangulation of the outcomes provided $t$ a complete overview of the activity. The results of each technique were merged and we developed the general findings that are presented in this paper.

In the next section, we present some of the observations which emerged and a set of design recommendations.

\section{THE CASE STUDY}

The study reported here is emblematic of the various studies we conducted within the last four years (see Table 1). The focus of this study has been on a specific DST activity where children were asked to create a story by taking inspiration from a school trip. This activity aimed to stimulate children's creativity, so that they could elaborate their experiences and make sense of what they encountered. The table shows the various stages of the 4-year longitudinal study we conducted. The thicker border highlights the study stage described in this paper.

Table 1. The longitudinal study stages

\begin{tabular}{|c|c|c|c|}
\hline Year & Grade & \# Students & Teacher \\
\hline \multirow{2}{*}{1} & $3^{\text {rd }}$ & 20 & T2 \\
\hline & $4^{\text {th }}$ & 18 & T 1 \\
\hline \multirow{3}{*}{2} & $3^{\text {rd }}$ & 20 & T 3 \\
\hline & $4^{\text {th }}$ & 20 & T2 \\
\hline & $5^{\text {th }}$ & 18 & T 1 \\
\hline \multirow{3}{*}{3} & $1^{\text {st }}$ & 22 & T1 \\
\hline & $4^{\text {th }}$ & 20 & T3 \\
\hline & $5^{\text {th }}$ & 18 & T 2 \\
\hline \multirow{3}{*}{4} & $1^{\text {st }}$ & 22 & T2 \\
\hline & $2^{\text {nd }}$ & 22 & T1 \\
\hline & $5^{\text {th }}$ & 22 & T 3 \\
\hline
\end{tabular}

Before the outing, children gathered information on the school trip's theme. During the trip they used tablets to record videos and to take pictures and notes. Afterwards they were asked by their teacher to create a story. The task was to produce a narrative inspired by the field trip topic but not about the field trip itself.

Before starting to create the stories, workgroups were organized. The teacher divided pupils in to five groups of four, assigning a tablet to each team. The teacher combined children in order to have a good balance of narrative and social skills in each 
group. Pupils identified characters and created the structure and the plot of their stories. A presentation software (Keynote ${ }^{\mathrm{TM}}$ ) was used to compose the story: each group produced a digital presentation made of several slides. Afterwards pupils presented their work to the whole class. Children spent two hours per week on the narrative activity and it took them three weeks to complete it.

\subsection{Findings}

To guide the activity analysis and to organize our findings we used the Narrative Activity Model (NAM) [3]. This model describes the four stages of narrative creation: exploration, inspiration, production and sharing. Through exploration pupils interact with the environment (e.g. a field trip). During the inspiration phase children understand the different aspects of their experience and dissociate from it: in this phase they analyze and reflect upon what they experienced. In the production phase, children elaborate new content using different expression modalities; in this stage children externalize the product of their imagination and express their emotions by producing a story. Sharing is the last phase of the narrative activity: at this point children share their stories with the external world. Children usually employ different expression modalities, ranging from verbal to bodily, and including multimedia elements such as music. Below we discuss the main aspects which emerged from stories created by children and inspired by the field trip.

\subsubsection{Enrich the teaching/learning experience.}

It goes without saying that the use of mobile technology had a strong influence on teaching practices. In our case, teachers needed to adapt their strategies to exploit the potential offered by mobile devices and Internet inside the classroom. The use of tablets for creating stories had an impact also on other aspects of teaching and stimulated teachers to include digital media in different activities. For instance, teachers introduced multimedia content - i.e. video alongside traditional textbooks. Teacher: "the use of technology in class makes me more stimulated in finding new on-line resources to teach the same topic using different media. I always started explaining a new topic with the support of a textbook but then I show pupils some videos about this topic. I notice that they are more engaged and remember better the content". The use of tablet activity also supported other educational activities in class and prompted the development of new educational practices. The teacher reinforces this concept adding "...technology helps us to keep focused and motivated, and enforces a positive attitude towards the storytelling task."

Moreover pupils started to perceive the tablet as an instructional tool instead of a toy. The teacher claimed: "using tablet allows us to speak pupils' language. Their life is surrounded by technology while the school often proposes just the books. I am not saying that I don't want to use book anymore but that the integration of other digital artifacts in teaching practices can be of a great benefit."

\subsubsection{Support a better understanding of educational content}

From the teachers' evaluation of the stories created it became apparent that pupils understood content presented in class with the help of digital technology better then compared with a situation where technology was not used. The teacher commented enthusiastically "... It has been an exciting experience for my pupils as they improved their writing skills and they learned how to discuss and share their abilities at the same time." Teachers considered tablet as an important element to prompt children's engagement and stimulate them in creating media and working on story development. The teacher: "I could see it from this experience. Using tablet ${ }^{\mathrm{TM}}$ for story creation stimulates them in being more engaged also in other activities in class."

Children's self-esteem regarding the use of digital devices increased as explained by the teacher "...my pupils would also like to write their class assignments using their tablets, they asked for that explicitly. All pupils in my class have a tablet at home. They feel so confident about using it that they offered to help one of their classmate's fathers who is involved in a project for the creation of stories."

\subsubsection{Encourage the pupils' creativity and their collaboration habits.}

The use of the tablet enabled a diversification of children's roles in the group according to their individual talents. The teacher: " children distributed the work among the group members for building the story. They took common decisions according to their abilities and the abilities of others. I have noticed that they mapped their abilities according to the applications available in the tablet. These allowed them to have a more clear idea of the different content to produce and the opportunity for each member to contribute to the story development." Indeed, having one tablet per group "forced" children to collaborate: "... the tablet was suitable to support group work and collaboration. It is close to the metaphor of the page. Children put it in the center of the desk and then they start working on the tablet as on a piece of paper." Furthermore, the balance in class among peers was positively affected, "Pupils that are weak in curriculum disciplines but who have strong competences in using technology became the point of reference for the others". 


\subsection{Requirements for the design of a mobile DST application}

Starting from the above mentioned findings we defined a set of design recommendations to drive the design of a DST application to be used in a formal learning context such as the one of [12] elementary school. We identified four main functionalities that in our opinion should constitute the four cornerstones of a DST application:

\section{Definition of story structure and plot \\ II. Media creation and editing \\ III. Sharing within the class \\ IV. Publication of the story.}

Each dimension corresponds to a specific moment in the process of story conception and creation. It is worth noting that these dimensions recall the NAM model's phases. Following, we provide more details for each dimension: a list of guidelines and user needs that a DST application should satisfy.

\section{Definition of story structure and plot:}

- to have various frameworks according to the type of the story (i.e. fair tale, fable, tale, myth and legend);

- to provide a clear content architecture for each story type (e.g. beginning, development and end of the story);

- to offer the "list of ingredients" according to the story type (e.g. the antagonist, the hero, the magic object);

- $\quad$ to provide the character archetypes and some representative images (e.g. the good king, the ugly princess, the smart cat);

- to allow children access to a set of hints to stimulate their creativity (e.g. what are the characteristics of the magic element of the story?);

- to have a spelling and grammar check tool, and a vocabulary;

\section{Media creation and editing:}

- to allow mobility of children both inside and outside the classroom (i.e. field trip);

- to use the same device for creating, assembling and editing the story;

- to translate any analog content to the digital media and to transfer them from one device to another (e.g. from tablet to desktop computer);

- to access the Internet in order to gather new content such as images, audio files, short movies, etc.;
- to allow the creation of multimedia experience (e.g. sound connected to images);

\section{Sharing within the class:}

- to allow children to see what the others are doing for taking inspiration - visibility of others' work;

- to obtain immediate feedback on the progress of the story while they are working on it - what you see is what you get.

\section{Publication of the story:}

- to allow children to show their story to their family: this is important for their agency and self-esteem;

- to allow the delivery of the story in different formats - e.g. web site, video, paper, etc.;

- $\quad$ to organize the story by different themes as in a virtual bookshelf;

- to rate the story.

As previously discussed, these guidelines implicitly take into consideration the NAM stages and the interactions among these different stages. Based on NAM we built an activity model of how children use the tablet to create their stories. From the study it emerged that these phases are not necessarily sequential. Indeed, often there are quick iterative cycles from one stage to another - e.g. production comes right after exploration without passing through inspiration. Our design recommendations considered this aspect: for instance the guidelines listed in II are intertwined with the guidelines listed in III. This means that the DST application should allow children to produce the story and immediately share it with their classmates.

\section{CONCLUSIONS}

In our project we aimed at understanding how to design an application that supports digital storytelling as educational practice in schools. Employing a longitudinal approach we have deeply investigated teaching and learning activities in an elementary school [Rubegni, E., Landoni, M., (2013) Modeling the role of teachers in introducing portable technology to the school curriculum, ECCE 2013 (forthcoming, 10 pp.)] .

We observed how the introduction of mobile devices impacted on the learning process and affected the interaction between teachers, learners and educational processes. Teachers and their interpretation of educational objectives provided an invaluable insight in the development of the guidelines. Digital technology was integrated with other artifacts that pupils commonly use in their educational practices. Overall, the participants reported the experience as being positive and 
stimulating in all its aspects. In particular, teachers began to use technology more often as pupils asked to use tablets for other activities besides storytelling. By focusing on the complete learning experience and by including all its stakeholders, processes, inputs and outcomes in the investigation, we elicited various user needs and identified a set of design recommendations for the development of a mobile DST application.

The originality of our approach is that we have considered how to provide each stakeholder with a fruitful teaching and/or learning experience going beyond the introduction of specific technology in school. Indeed, at the beginning of the project a big effort was made by the researchers to combine the project objectives with the school's pedagogical goals. Furthermore, we spent sometime at the school to find a way to introduce technology, making it a resource for teachers and students which would effectively support their curriculum.

\subsection{Limitations and future work}

As main limitation, the case study was carried on only in one school, thus the data gathered refers to this specific context. Nevertheless, we planned to carry on a long-term study in one context in order to go in depth on a specific complex reality and investigate the different nuances of these educational practices.

At the moment we are evaluating the prototype developed following the design recommendations previously mentioned. The evaluation has been done in several schools in order to have a wider corpus of data and more feedback. In the near future, we plan to refine the application and to investigate how digital artefacts stimulate or hinder children's imagination

\section{REFERENCES}

1.Blumenfeld, P., Fishman, B. J., Krajcik, J., Marx, R. W., \& Soloway, E. (2000). Creating usable innovations in systemic reform: Scaling up technology-embedded project-based science in urban schools. Educational Psychologist, 35(3), 149-164

2.Bruner, J.S. (1996). The culture of education. Cambridge MA: Harvard University Press Cassell, J., and K. Ryokai (2001) 'Making Space for Voice: Technologies to Support Children's Fantasy and Storytelling', in Personal Ubiquitous Computing 5, 3, pp.169-190

3.Decortis F. and A. Rizzo (2002) 'New active tools for supporting narrative structures', in Personal and Ubiquitous Computing, 6(5-6), pp.416-429

4.Halloran, J., Hornecker, E., Fitzpatrick, G., Weal, M., Millard, D., Michaelides, D., ... \& De Roure, D. (2006, June). The literacy fieldtrip: using
UbiComp to support children's creative writing. In Proceedings of the 2006 conference on Interaction design and children (pp. 17-24). ACM

5.Kukulska-Hulme, A., Evans, D., \& Traxler, J. (2005). Landscape study in wireless and mobile learning in the post-16 sector. Retrieved October, 14, 2005.

6.Naismith, L., Lonsdale, P., Vavoula, G., and Sharples, M., (2009) Literature Review in Mobile Technologies and Learning, Report 11. FutureLab Series. 2009

7.Nicolopoulou, A. (1997). Children and narratives: toward an interpretive and sociocultural approach. In M. Bamberg, Narrative development: six approaches (pp. 179-216). London: Lawrence Erlbaum

8.Nylander, S., Lundquist, T., \& Brännström, A. (2009, April). At home and with computer access: why and where people use cell phones to access the internet. In Proceedings of the 27th international conference on Human factors in computing systems (pp. 1639-1642). ACM.

9.Papert, S. (1991) 'Situating Constructionism', in Idit Harel and Seymour Papert (eds.): Constructionism. Norwood, NJ: Ablex Publishing

10.Pittarello, F., \& Bertani, L. (2012, June). CASTOR: learning to create context-sensitive and emotionally engaging narrations in-situ. In Proceedings of the 11th International Conference on Interaction Design and Children (pp. 1-10). ACM.

11.Raven, M.E., and Flanders, A. (1996). "Using Contextual Inquiry to Learn About Your Audience." ACM SIGDOC Journal of Computer Documentation, Vol. 20, No. 1

12.Rubegni, E., Landoni, M., (2013) Modeling the role of teachers in introducing portable technology to the school curriculum, ECCE 2013 (forthcoming, $10 \mathrm{pp}$.)

13.Rizzo, A., Marti, P., Decortis, F., Moderini, C., \& Rutgers, J. (2002). The Design of POGO Story World. Handbook of Cognitive Task Design, 577602.

14.Rogers, Y., Price, S., Fitzpatrick, G., Fleck, R., Harris, E., Smith, H., ... \& Weal, M. (2004, June). Ambient wood: designing new forms of digital augmentation for learning outdoors. In Proceedings of the 2004 conference on Interaction design and children: building a community (pp. 3-10). ACM.

15.Yarosh, S., Radu, I., Hunter, S., and Rosenbaum, E. (2011). Examining Values: An Analysis of Nine Years of IDC. In Proceedings of IDC 2011, ACM Press (2011), 136-144 